\title{
"A autoestima é muito importante": \\ a retórica da salvação pessoal nos relatos de celebridades sobre o bullying ${ }^{1}$
}

\section{Igor Sacramento ${ }^{2}$}

Resumo: Este artigo tem como objetivo analisar os relatos de celebridades sobre o bullying no programa Encontro com Fátima Bernardes para mostrar como o discurso terapêutico produz a normatização da subjetividade contemporânea baseada na ideia de autoestima. Os testemunhos considerados neste texto são sobre o racismo e sobre a importância do trabalho na superação da experiência de bullying. Explico que há uma mudança significativa no teor de testemunhos sobre sofrimentos: da narrativa da sobrevivência para a da resiliência.

Palavras - Chave: Celebridades. Televisão. Autoestima. Bullying. Resiliência.

Abstract: This article aims to analyze the celebrity's testinonies about bullying in the TV talk show Encontro com Fátima Bernardes to show how the therapeutic discourse produces the norms of contemporary subjectivity based on the idea of selfesteem. The testimonies considered in this text are about racism and about the importance of work in overcoming bullying experiences. I explain that there is a significant change in the testimonies of suffering content: from a narrative about survival to a narrative about resilience.

Keywords: Celebrities. Television. Self Esteem. Bullying. Resilience.

\footnotetext{
1 Este artigo é um dos resultados do projeto de pesquisa "Diante da dor dos célebres: o ethos terapêutico nos testemunhos televisivos de sofrimentos íntimos", realizado com apoio do CNPq no âmbito do edital de Ciências Humanas, Sociais e Sociais Aplicadas.

${ }^{2}$ Doutor em Comunicação e Cultura pela Universidade Federal do Rio de Janeiro e pesquisador do Laboratório de Pesquisa em Comunicação e Saúde do Instituto de Comunicação e Informação Científica e Tecnológica em Saúde da Fundação Oswaldo Cruz. E-mail:
} igor.sacramento@icict.fiocruz.br 


\section{Introdução}

Na cultura contemporânea, o discurso terapêutico não se dá somente pela interpelação os indivíduos como sujeitos autorrealizadose pela promoção do reconhecimento da autolimitação. Produz o self numa forma nitidamente frágil e vulnerável, em que a gestão da vida requer a intervençãoo contínua de especialização terapêutica (FUREDI, 2004), mas também necessariamente adaptável às situações adversas para desenvolver a capacidade individual de superação (ILLOUZ, 2003). A cultura da mídia contemporânea confere ao discurso terapêutico uma intensa permeabilidade no tecido social por meio da produção, circulação e consumo de inúmeros produtos (livros de autoajuda, revistas, programas de TV e rádio, sites, redes sociais e comunidades virtuais de ajuda mútua). Assim, é cada vez mais comum transformar a percepção de divórcios, do desemprego, das dificuldades econômicas, das situações de bullying e das doenças crônicas, por exemplo, como experiências de vulnerabilidade e sofrimentos que podem ser convertidas em "lições de vida", quando combinadas com uma trajetória de busca pela superação baseada na autogestão emocional (SACRAMENTO, 2015; 2016). Os indivíduos capazes de transformar essas experiências em motor para a promoção do auto melhoramento são considerados exemplares do treinamento da resiliência, ao mesmo tempo que este seja um comportamento seja cada vez mais normalizado e de acordo com a expectativa social diante dos sofrimentos. É certo que o aumento da circulação do discurso terapêutico na vida social enfatiza a vulnerabilidade como condição definitiva da existência humana e promove a resiliência como capacidade individual tanto de resistir às mudanças súbitas ou a situações de estresse quanto de se recuperar e retornar ao estado de felicidade e prazer (FUREDI, 2004). Mas tal discurso também promove a valorização da recuperação constante (porque sempre incompleta e interminável) ao invés da cura.

Nesse contexto, as celebridades são cada vez mais interpeladas a assumirem posições de vítimas de situações de sofrimento para, assim, promoverem um conjunto de valores legitimados na sociedade contemporânea: a autenticidade 
(por serem fiéis consigo mesmas no momento em que relatam suas angústias), a sinceridade (por contarem aquilo que realmente aconteceu com elas para o público), a intimidade (por tornar necessária a simulação do contato íntimo - o "calor humano"- para a sociabilidade contemporânea) e a visibilidade (por caracterizar a exposição de si por meio de tecnologias de comunicação diversas como prática fundamental aos processos de subjetivação e de relação social) (SACRAMENTO, 2015). Desse modo, as celebridades afirmar sua autoridade não mais por se configurem como semideuses (MORIN, 1977), mas sobretudo por exporem suas angústias, frustrações, problemas e conflitos que conferindo maior humanidade e pessoalidade, que se mostram como "realmente são" (LITTLER, 2004). Com isso, elas podem se tornar modelos de ação na medida em que conseguem recuperar ou conquistar a felicidade por meio da autoestima.

O objetivo deste artigo é, a partir de relatos de celebridades sobre o bullying exibidos pelo programa, mostrar como o discurso terapêutico contemporâneo se articula a regimes televisivos de visibilidade para configurar a autoestima diante de eventos traumáticos como dispositivo de identificação e disciplinamento dos sujeitos sofredores. Para tanto, dividi o texto em duas partes, para além desta introdução e das considerações finais. $\mathrm{Na}$ primeira, abordo a transformação do racismo em bullying em determinados relatos e, depois, como outras narrativas pessoais tomam o trabalho como elemento fundamental para a superação do sofrimento e para a salvação pessoal.

A escolha do programa Encontro com Fátima Bernardes se deveu ao fato de o programa procurar ter um clima informal, remetendo à encenação do ambiente doméstico (uma sala de estar, onde a apresentadora recebe os seus convidados num enorme sofá no centro do estúdio). O programa, assim como outros talk shows, promove uma mistura de temas de interesse público com a vida privada, ao enfocar em acontecimentos cotidianos discutidos por meio de relatos pessoais de anônimos e de celebridades. Conta, assim, com uma forte estratégia de pessoalização discursiva. As histórias contadas são pessoais, tendo o intuito de constituir uma relação de intimidade e de identificação com o público mediada pela apresentadora. São frequentes no programa temas sobre saúde, traumas, doenças, comportamento, 
moda, qualidade de vida, histórias de superação, beleza, relacionamento, economia doméstica, música e fama.

Encontro com Fátima Bernardes estreou no dia 25 de junho de 2012. É exibido de segunda a sexta, às 10h50min, após o programa Bem-Estar. Além de Fátima Bernardes, conta em seu elenco fixo com Marcos Veras (ator) e Lair Rennó (jornalista). Com certa regularidade, também participam do programa, num clima informal de conversa com os convidados, o neurocirurgião Fernando Gomes Pinto, o poeta Fabrício Carpinejar, a dermatologista Daniela Alvarenga, a filósofa Viviane Mosé, a psicanalista Lígia Guerra, a educadora Andrea Ramal e o psicanalista Moisés Groisman. Eles atuam não apenas como especialistas, mas, sobretudo, como interlocutores daqueles que narram suas histórias de vida.

A partir do acesso ao acervo de vídeos do programa pelo site [1] com uma busca pela palavra bullying realizada em 15 de agosto de 2015, foram encontrados 16 depoimentos de celebridades: Renatão (16/07/2012), Serjão Loroza (09/07/2012), Daniel Rocha (19/07/2012), Paula Braun (18/11/2013), Leonardo Miggiorin (18/11/2013), Thiago Brava (23/03/2014), Lucas Salles (23/03/2014), Polliana Aleixo (23/03/2014), Fabrício Carpinejar (13/08/2014), Cristiana Oliveira (02/12/2014), Marcelo Serrado (10/03/2015), Marcos Caruso (18/05/2015), Fernanda Vasconcellos (28/05/2015), Juliana Alves (03/06/2015), Ana Paula Henkel (13/o8/2015) e Emmanuelle Araújo (13/o8/2015).

Para este artigo, por conta das limitações de espaço, optei por analisar dois dos três eixos temáticos que identifiquei: 1) a terapia da autoestima; 2) o trabalho como salvação pessoal; e 3) o racismo transformado em bullying. $\mathrm{O}$ primeiro eixo contempla um conjunto de depoimentos em que a necessidade de aprimorar por capacidade individual de autoestima para poder superar os eventos de violência motivada pelo preconceito e pela intimidação. Este foi objeto de outro artigo (SACRAMENTO, 2016). Os outros dois são objetos deste. Como demonstro, embora o receituário da autoestima esteja presente em todos os relatos da amostra identificada, em dois (no de Juliana Alves e de Serjão Loroza), o racismo é identificado como bullying e, em outros, a prática profissional é entendida como um processo de melhoramento de si diante das marcas deixadas na psique e na experiência pela 
submissão ao bullying, como nos casos de Leonardo Miggiorin, Lucas Salles, Thiago Brava, Ana Paula Herckel e Marcelo Serrado.

A análise dos depoimentos levará em conta como a pessoalização se configura como estratégia argumentativa para garantir o estatuto de veracidade da experiência relatada, mas também como modo de testificar a superação bemsucedida do passado traumático. No processo de pessoalização discursiva, o "eu" da narrativa testemunhal conta com uma dupla função: de mediação entre o íntimo e o público e de referencialidade. As duas são calcadas na experiência pessoal dos fatos e , portanto, na narração dos próprios sentimentos : naquilo que só o “eu” pode tornar público e dizer que é verdade (RIBEIRO e LERNER, 2005: 215-216). O testemunho é uma "narrativa contada na primeira pessoa gramatical por um narrador que é ao mesmo tempo o protagonista ou a testemunha do evento relatado" (BEVERLEY, 2004, p.31), tendo como unidade narrativa uma experiência particularmente significativa. Além disso, o testemunho é exemplar, profundamente marcado pela oralidade; é uma narrativa que visa, antes de tudo, o particular e que tem como finalidade "a estruturação de um discurso de certo modo tipificador" (SELLIGMANSILVA, 2005, p.92), uma vez que cria regras para o comportamento dos protagonistas, designa fronteiras e vínculos entre enunciador e enunciatário e estabelece valores morais, exemplares, a serem seguidos e defendidos.

Há, como explico ao longo do texto, um teor testemunhal nos relatos das celebridades sobre suas experiências pessoais com o bullying, na medida em que abordam eventos do passado como pontos de partida para a superação futura.

\section{A transformação do racismo em bullying}

Em 9 de julho de 2012, Fátima Bernardes conversou com o ator e cantor Serjão Loroza sobre bullying:

FÁTIMA: Você se lembra de alguma situação de incômodo que hoje podemos chamar de bullying? 
SERJÃO: Claro! Preto, pobre, suburbano, gordo, é tudo junto, só faltou ser judeu convertido e torcedor do América, o resto, todas as minorias possíveis e imagináveis, era eu mesmo.

A resposta de Serjão Loroza é de absoluto humor, transformando o preconceito em algo risível e, ao mesmo tempo, justificando os atos discriminatórios pela multiplicidade de marcações sociais da diferença com que era identificado ("preto, pobre, suburbano, gordo"). A apresentadora, então, procura dar seriedade ao assunto e pede que ele fale sobre como o bullying o ajudou a se tornar "mais forte":

SERJÃO: De uma certa maneira, isso me ajudou a ter resiliência [voltandose o olhar para a psicanalista Lígia Coelho, que lhe sorri]. Gostei dessa palavra. Agora, vou usar toda hora. Eu sou uma pessoa resiliente, sabe? Eu comecei a me utilizar disso. Quando me chamaram de criolo, eu não me irritava. O criolo não era mais ofensivo para mim, e eu comecei a tornar aquilo bom, que me deixava forte, mais conhecido por todo mundo, mais engraçado e malandro.

FÁTIMA: Qual o apelido que te irritava mais?

SERJÃO: Para mim, de todos os apelidos, o macaco, o gorila, doía muito. Eu não sei explicar o porquê, mas doía muito. Deve ter a ver com aquela coisa do Darwin. O macaco não é nem gente, nem humano ainda...

FÁTIMA [interrompendo]: Serjão, como é que você vira isso?

SERJÃO: A autoestima é muito importante. A arte me ajudou muito nisso. Eu queria muito ser querido, amado, o aplauso e não a ofensa que vivi com tanta frequência. Queria buscar o carinho, o amor, para me fortalecer [grifos meus].

Nesse momento da entrevista, fica evidente a tentativa da apresentadora em diminuir o tom jocoso e dar maior gravidade à abordagem do assunto ("Qual o apelido que te irritava mais?”). O humor do entrevistado estava tripudiando com a estrutura narrativa formatada pelo programa para esse tipo de relato: da experiência de sofrimento à superação, por meio da qual o depoente se coloca como modelo de sucesso e conduta. Ao contrário disso, ele já apressadamente se identificou como "resiliente" e afirmou que o fato de ser chamado frequentemente de criolo não era mais visto como uma ofensa, mas como uma possibilidade de afirmação identitária (“Eu sou uma pessoa resiliente, sabe?).

Antes do relato do artista, a psicanalista Lígia Coelho explicou que indivíduos que sofrem bullying devem "treinar" o aprimoramento de sua capacidade de resiliência. Nas palavras dela, eles devem buscar "enfrentar os problemas, superar 
os obstáculos, resistir às pressões", tendo como objetivo principal "vencer as adversidades". Desse modo, como já abordei inicialmente, a relação entre autocontrole e autoestima tornou-se tão intensa, num contexto de psicologização da sociedade, que até mesmo questões sociais graves como o racismo são transformadas em bullying. Mais do que isso, cobra-se da vítima uma gestão emocional tal que permita resistência e recuperação diante das manifestações e situações preconceituosas. Assim, a autoestima tornou-se algo como uma "vacina social" que habilita as pessoas a viverem uma vida responsável, segura e afortunada (CRUIKSHANK, 1996, p.232). Isso, certamente, reforça a reorientação da resolução de problemas sociais em torno do eu. Afinal, o discurso contemporâneo de autoestima leva a governamentalidade ainda mais para dentro da esfera íntima, interioriorizada, da própria formação do ideal atual de subjetividade, onde eu se torna a um só tempo subjetivação, controle e imagem. Os indivíduos são cada vez mais instados a assumir, assim, o objetivo de aprimorar a si mesmos, a fim de alcançar a realização pessoal e para cumprir sua obrigação com os preceitos da sociedade atual. O discurso da autoestima é parte de uma tecnologia de poder que molda a subjetividade contemporânea e guia os indivíduos na condução de suas vidas, com o auxílio de uma variedade de profissionais (psicólogos, terapeutas e os autores de autoajuda literatura, mas também celebridades, jornalistas e apresentadores) e de um conjunto diversificado de técnicas para desenvolver a autoestima e o autocontrole. Nesse sentido, não surpreende que a psicanalista Lígia Coelho tenha sugerido às vítimas de preconceito que "treinem" a sua capacidade de resiliência. Afinal, uma vez que a interioridade psicológica passou a ser um dos territórios da ação da governamentalidade nas sociedades liberais contemporâneas, expandem-se as terapias de estilo de vida (lifechoaching) e, portanto, o entendimento de que viver demanda a necessidade de treinamento psicológico (BINKLEY, 2011). Atualmente, entendemos generalizadamente que viver exige a busca por formas de aperfeiçoamento pessoal. Esse entendimento é, também, associado à produção e à circulação de imagens de si. A produção subjetividade contemporânea, fundamentada no ideário da autoestima, articula-se à exposição de imagens pessoais de processos de sofrimento e de superação, em jogos performativos da busca e da 
conquista de uma vida feliz, legitimada pela visualização e estimulação de audiências (telespectadores, internautas, leitores).

Palavra frequente nas edições analisadas do programa, resiliênciaé uma noção que tem uso originário na ecologia e na engenharia. Trata-se da capacidade de se recuperar ou retomar à forma original depois de compressão ou flexão. A sua adoção subsequente pelo campo da psicologia servira para medicalizar essa noção numa orientação de conduta e acabou destacando a qualidade de ser capaz de lidar com a adversidade e se recuperar rapidamente. A tentativa da psicologia para entender como a resiliência pode ser promovida é um objetivo frequente. $\mathrm{Na}$ psicologia positiva, muitas vezes busca-se transformar traços de personalidade em habilidades que possam ser aprimoradas através de técnicas de gestão de comportamento (BINKLEY, 2011; FUREDI, 2004; ROSE, 1990). Associando valores morais associadas à medicalização do comportamento, a noção de resiliência como base para desenvolvimento de técnicas de aprimoramento do gerenciamento individual das emoções legitima a intervenção psicológica de modo a ensinar os indivíduos a desenvolverem atitudes e habilidades necessárias para torná-los resilientes.

Ao se identificar como crioulo, vascaíno e resiliente, Serjão Loroza transformou a questão da discriminação racial numa problematica psicológica, submetida à capacidade individual de gerenciar as emoções e transformar os sofrimentos vividos em "material [que será internamente] reciclado" para promover o desenvolvimento pessoal (ILLOUZ, 2003, p.230). Este é um procedimento narrativo bastante popular nos programas televisivos que abordam dramas pessoais. Neste caso, ele produz um apagamento da questão social da discriminação em suas múltiplas formas (em relação à sexualidade, ao gênero, às formas corporais, à aparência, à raça) com a ênfase nos problemas psicológicos que geram nos agredidos, na identificação de disturbios psicológicos nos agressores e, sobretudo, nas histórias de superação das vítimas na conquista de uma vida feliz e prazerosa (ILLUOZ, 2003). Assim, a experiência dele pode ser vista não tanto como uma evidência da eficácia da resiliência como um conjunto de técnicas psicológicas, mas da configuração social de um sujeito que se sente impelido a não sucumbir ao sofrimento, mas ser resiliente, 
mesmo que não tenha frequentado formalmente sessões de terapia. A experiência social contemporânea é permeada por orientações de conduta e modelos de superação de sofrimentos para exercitar publicamente a autoestima.

Daí a necessidade de conferir um teor testemunhala os relatos pessoais das celebridades no programa. Mas não se trata de um teor tal como aqueles dos relatos de sobrevivente de tragédias, no qual se dá primeiramente uma relação metonímica entre o real e a narrativa, não como a realidade representacional das estéticas realistas e naturalistas, mas como que um trauma que impõe ao evento vivido resistir à representação (SELLIGMAN-SILVA, 2005). Na narração do trauma, a relação de quem testemunha com a linguagem é de falta, de ausência, de impossibilidade completa de expressão da experiência; é nisso que se concentra o estatuto de verdade de testemunhos desse tipo: "a linguagem é antes de mais nada o traço - substituto e nunca perfeito satisfatório" (SELLIGMAN-SILVA, 2003, p.48).

Já no programa Encontro com Fátima Bernardes, o teor testemunhal dos relatos das celebridades que sofreram com o bullying está especialmente no seu valor dramático, ou seja, em sua plena capacidade de representação e de expressão do sofrimento pelas vítimas por meio de linguagem verbal e não verbal. A veracidade do relato do ator é medida pela exposição do sofrimento, mas sobretudo pela apresentação de práticas positivas que o levaram à superação das experiências negativas. Afinal, o que está em jogo na configuração contemporânea da subjetividade é a capacidade de gerenciamento eficaz de si, tornando-se mais autoconfiante, sempre buscando autoconhecimento e desenvolvimento pessoal. Desse modo, a narração do trauma na cultura terapêutica contemporânea é uma forma valorizada da capacidade individual de manter a própria "saúde afetiva" e transformar a experiência de sofrimento em narrativa de aconselhamento para o público (ILLOUZ, 2012, p.81).

Frequentemente, a rememoração midiática da experiência de sofrimento é baseada na "ética da autonomia" e na "retórica da escolha", que assumiram o centro dos processos de subjetivação (RAINBOW e ROSE, 2006, p.24). Afinal, nas sociedades liberais contemporâneas, governa-se através de escolhas reguladas de cidadãos, que são constituídos como sujeitos de escolhas e com aspirações de 
autorrealização (ROSE, 1990). Não são, portanto, meramente obrigados a escolher, mas obrigados a escolher para compreender e conduzir suas próprias vidas. Essas práticas expõem a formação característica na qual as escolhas ensejam novas formas de responsabilização e conferem às próprias escolhas obrigações do cálculo racional sobre riscos futuros pelas ações realizadas ou não no presente, que fica cada vez mais comprometido pela busca de um futuro seguro, saudável e feliz: bem-sucedido.

Serjão Loroza, por fim, se ajustou ao encadeamento narrativo esperado pelo programa e tornou positiva a ofensa ("eu comecei a tornar aquilo bom, que me deixava forte, mais conhecido por todo mundo, mais engraçado e malandro"), ainda que reforce estereótipos comumente associados aos negros no Brasil como o bom humor, a malandragem e a força (SODRÉ, 1999). Embora a positivação do sofrimento numa trajetória de superação seja valorizada, há a expectativa de que isso se dê como a moral da história e não como o seu início. Nesse sentido, Fátima Bernardes buscou a revelação de alguma experiência de sofrimento promovida por algum apelido, mas logo interrompeu o entrevistado para saber como o sofrimento o tornou mais forte. Então, assim, obteve a moral da história: “A autoestima é muito importante".

No programa do dia 3 de junho de 2015, a atriz Juliana Alves também relatou a discriminação racial vivida na infância como bullying:

FÁTIMA: Você sofreu muito bullying racial, Juliana?

JULIANA: Vivi, vivi bastante. Até um determinado momento eu achava que não deveria me aborrecer com isso, que eu não tinha o direito de me sentir incomodada, que era só uma brincadeira mesmo. Mas os meus pais são muito esclarecidos sobre isso, e eu fui percebendo que a gente realmente não pode e não deve aceitar esse tipo de brincadeira. Eu dizia para os meus amigos o seguinte: "Eu sou sua amiga, eu quero brincar com você, contanto que a sua brincadeira seja respeitosa, respeite as minhas raízes, respeite a minha natureza. Afinal, eu respeito a sua natureza. Então, você tem que aprender a conviver comigo, até mesmo que para a sua família isso seja estranho".

FÁTIMA: E o que normalmente era estranho? A pele, o cabelo...

JULIANA: Era o cabelo. Meu maior bullying era com o cabelo. Nossa! Mas eu vejo as minhas sobrinhas, elas vivem um pouco isso, mas é um pouco melhor. Não estou dizendo que acabou, pelo contrário! Mas a questão da lei foi importante. Os pais estão tendo mais cuidado sobre o que falar para os filhos, mas está cada vez mais claro que é uma questão de educação, de cultura, principalmente.

FÁTIMA: Mas o que te fez superar? 
JULIANA: Além dos meus pais, que sempre foram muito esclarecidos sobre isso e que me fizeram ter orgulho da minha natureza, o trabalho ajudou muito. O que era visto como estranho passou a ser reconhecido como beleza. O trabalho me fez mudar, me sentir melhor, mais confiante. [grifos meus]

O relato de Juliana Alves demonstra claramente o processo de configuração da subjetividade num contexto social marcado por políticas de reconhecimento ("Eu sou sua amiga, eu quero brincar com você, contanto que a sua brincadeira seja respeitosa, respeite as minhas raízes, respeite a minha natureza”). A política das diferenças é uma das características centrais da sociedade contemporânea, em que se tem tornado fortemente imbricada à democracia a necessidade do reconhecimento. Essa associação é facilmente identificado pela proliferação e atuação de movimentos feministas, gays, transgêneros, étnico-raciais, multiculturalistas e outros. A importancia específica de reconhecimento reside na sua relação com a identidade. Ou seja, a identidade moderna é moldada pela dinâmica entre o reconhecimento e o não reconhecimento. O reconhecimento é "uma necessidade humana vital", e o não-reconhecimento pode "infligir uma ferida grave, selando suas vítimas com um auto-ódio incapacitante" (TAYLOR, 1994, p.26). Além disso, não ter a identidade reconhecida pode ser uma forma de opressão, aprisionando alguém em um "modo falso, distorcido e reduzido de ser" (TAYLOR, 1994, p.25).

Sendo assim, Juliana Alves compreende que a aceitação da diferença está no cerne dos ideais democráticos contemporâneos ("Então, você tem que aprender a conviver comigo, até mesmo que para a sua família isso seja estranho"). Na contemporaneidade, intensifica-se a noção moderna de dignidade, que assenta em princípios universalistas sobre o valor igual de todos os seres humanos. Nesse sentido, negar o reconhecimento a pessoas negras como Juliana Alves passa a ser considerado não apenas preconceituoso, mas sobretudo antidemocrático. Por outro lado, é interessante observar o quanto a aceitação da diferença no programa também apareceu como uma forma de marcação social do diferente. A apresentadora pressupõe a discriminação vivida pela atriz quando criança ("E o que normalmente era estranho? A pele, o cabelo...”). Desse modo, não se deve negar que a política da 
diferença não abole as hierarquias identitárias tradicionais (TAYLOR, 1994), mas estabelece novas formas de hierarquização: a normatização de uma imagem adequada do ser negro e a separação entre "nós" e "eles" internamente à comunidade negra e externamente, em relação aos brancos (APPIAH, 1994, p.163).

Na mesma edição do dia 3 de julho de 2015, a apresentadora conversa com Lorena, uma estudante da Faculdade de Artes da Universidade de Brasília, que iniciou uma campanha intitulada “Ah, Branco, dá um tempo...”, em que combate o racismo velado. Pessoas negras são abordadas para escrever num cartaz alguma manifestação de racismo que já sofreram e posam para uma foto empunhando-o. Lorena se emociona bastante no final da conversa: “A minha voz é a voz de vários universitários negros pelo Brasil, que reproduziram essa campanha para mostrar o quanto que a gente é forte, o quanto dói falar do nossos cabelos, da nossa pele, dos nossos traços”. Logo após a fala, Juliana Alves diz que se identificou com a história de Lorena, levanta, vai ao encontro dela, a abraça e não consegue conter as lágrimas: "Tenho muito orgulho de ver que se multiplicam pessoas como você. Sinto esperança no coração".

Esses relatos demonstram que a aceitação da negritude passa por uma normalização de uma forma adequada de ser negro, afirmando a necessidade de manutenção de traços tidos como naturais como o cabelo. Dessa forma, a identidade negra está vinculada à natureza. Assim, ao valorizar uma identidade particular, os indivíduos que não possuem determinadas características valorizadas pelo grupo podem ser classificados como inferiores, mais submetidos à moralidade e ao padrão estético da dominante. Por exemplo, mulheres negras que alisam o cabelo podem ser vistas como indivíduos que não reconhecem a sua própria natureza, mas se submete aos desígnios da branquitude. Por isso, tanto Juliana Alves quanto Lorena se identificam: "Nós temos o direito de ter o nosso cabelo assim", disse a atriz depois do abraço emocionado na estudante. As duas mantém os cabelos crespos e volumosos.

O que se busca, portanto, é a aceitação de que outro padrão estético seja valorado como belo. Dentro da linguagem terapêutica contemporânea, aqueles que foram vítimas de preconceito racial devem buscar se afirmar e não se ajustar. Isso vem sendo frequentemente reconhecido como capacidade de gerenciamento do 
sofrimento de modo proativo, com autoestima e empoderamento. Assim, a discriminação racial é menos uma questão social grave e estrutural no Brasil do que um problema de gestão emocional pelas vítimas de preconceito na direção de uma vida bem-sucedida e feliz.

Em Encontro com Fátima Bernardes, nas duas edições que abordaram o que a apresentadora chamou de "bullying racial", houve a busca por tornar o tom mais sério, mesmo sem deixar a informalidade. As celebridades, nesse caso, produziam uma religação com o coletivo por meio de seus relatos não por uma narrativa da dor, mas da superação dele. Nesse aspecto, também funcionam modelos pessoais de autoestima, seja diante da discriminação racial ou de outros preconceitos. Assim, o discurso terapêutico contemporâneo, além de obliterar o social em detrimento do individual, transforma todos os acontecimentos que levam ao sofrimento como praticamente equiparáveis, uma vez que instaura um exercício narrativo e subjetivo: demonstrar pelo relato da experiência o movimento de passagem do sofrimento para a superação, e, assim, a própria capacidade de governar a si mesmo eficazmente.

\section{O trabalho como salvação pessoal}

Tanto no relato de Serjão Loroza (“A arte me ajudou muito nisso”) quanto no de Juliana Alves (“O trabalho ajudou muito”) há uma crença de que a carreira artística foi fundamental para a superação das experiências de bullying. No programa do dia 18 de novembro de 2014, o ator Leonardo Miggiorin conta que sofreu bastante no colégio:

FÁTIMA: Você carrega alguma coisa que você acha que ficou?

LEONARDO: Então, ficam algumas marcas. $O$ que aconteceu de legal na minha vida foi descobrir o teatro e fui trabalhando uma série de questões minhas. E eu sofria muito por causa das espinhas. Riam de mim, me xingavam. Era difícil para tudo, arrumar uma namorada e tal. Depois, eu fui fazer Presença de Anita e fui aprovado no teste pelo Manoel Carlos. Foi uma superação através do trabalho. Eu fui descobrindo minha identidade e o meu espaço através da arte. $\mathrm{E}$ até hoje estou aqui, muito melhor.

FÁTIMA: Que bom! 
Leonardo Miggiorin obteve repercussão nacional com o personagem Zezinho em Presença de Anita (2001), um adolescente que se apaixona perdidamente por Anita (Mel Lisboa) e a disputa com Nando (José Mayer), com quem ela tem um caso. $\mathrm{O}$ ator conta também que a escolha para o papel, além do talento, levou em conta o fato de ele ter espinhas. $\mathrm{O}$ autor da novela imaginava o personagem magro, tímido e com espinhas. Então, as características que foram alvo de zombarias e agressões de colegas da escola se transformaram em senhas de acesso ao estrelato.

Além disso, o relato do ator demonstra o quanto o discurso terapêutico contemporâneo interpela os indivíduos como sujeitos inseguros, infelizes e vulneráveis, que necessitam buscar pelo aperfeiçoamento pessoal nas mais diversas atividades para poderem se sentirem autoestima o suficiente para enfrentarem seus problemas e terem sucesso na vida (“O que aconteceu de legal na minha vida foi descobrir o teatro e fui trabalhando uma série de questões minhas”). Nesse sentido, a escolha pela carreira artística havia lhe possibilitado mais do que lidar com seus problemas pessoais: o sucesso pessoal. Fica evidente que a valorização do dinheiro e da liberdade individual na sociedade contemporânea estimulam um movimento na direção do "primeiro eu” (LIPOVETSKY, 2004, p.38). O trabalho, nessa configuração, assume o espaço próprio para o sucesso pessoal, uma vez que ele permite também aperfeiçoar a autoestima. Isso não se dá apenas pela fama, pelo reconhecimento do público, pelo êxito profissional. O trabalho no contexto contemporâneo não envolve apenas aptidões profissionais, mas também uma forma de "capacitação pessoal" constante (SENNETT, 2011, p.117).

O neoliberalismo criou não sónovas formas de governar com base na intervenção estatal mínima, mas também um novo tipo de sujeito: ativo, independente, ambicioso, assertivo, esforço, autorrealizável e responsável. Cruikshank (1999) argumenta que, nas democracias contemporâneas, o sujeito se torna uma questão de fazer-se para si mesmo. Com isso, os cidadãos assumem o objetivo de trabalharem em si mesmos, a fim de alcançar a realização pessoal e para cumprir sua obrigação para a sociedade. A força coercitiva das formas disciplinares de governo é substituída nas sociedades contemporâneas pelo autogoverno. Este é moldado e guiado por exércitos de profissionais (incluindo psicólogos, terapeutas, 
apresentadores de TV, celebridades e os autores de literatura de autoajuda). Este autogoverno parece emanar de uma busca autônoma para a compreensão e liberdade pessoal. A cidadania é atualmente constituída para ser ativa e individualista em vez de passiva e dependente. O sujeito político é, doravante, um indivíduo cuja cidadania é manifestada através do livre exercício de escolha pessoal entre uma variedade de opções (ROSE, 1990).

Como já demonstrei, a psicologia positiva desempenha um papel significativo no fornecimento de linguagem e padrões normativos para o ser humano. Ela desenvolve, assim, uma função crucial na fabricação da sociedade contemporânea (ROSE, 1990). Na verdade, as explicações psicológicas tornaram-se uma base para a nossa forma de interpretar nossas vidas seguindo os vocabulários de autorrealização e autoestima. Esses entendimentos e explicações dominam as culturas ocidentais, onde os indivíduos são atos em si mesmos, desde que de acordo com esses princípios.

É interessante observar a presença do vocabulário psicológico na conversa da apresentadora Fátima Bernardes com o ator. Ao identificarem que a experiência do trauma deixa marcas psicológicos nas vítimas, seguem o diálogo cotejando detalhes do sofrimento vivido. Tradicionalmente, a linguagem psicanalítica do trauma enfoca principalmente nas marcas deixadas pelo agressor na vítima como sintomas o modo de buscar a origem dos transtornos (HERMAN, 1992). Já a exposição do sofrimento por meio da linguagem terapêutica transforma a narração do trauma numa forma baseada num senso profundo de aconselhamento, no qual "o sofrimento é desconectado do contexto social e entendido como uma questão de gestão de si” (FUREDI, 2004, p.128). Assim, as vítimas que superam suas dores sentem a necessidade de se colocar como modelos públicos de conduta. Leonardo Miggiorin, particularmente, insiste em inicialmente em se posicionar como vítima ("Riam de mim, me xingavam") para depois de afirmar como herói de si mesmo (“Depois, eu fui fazer Presença de Anita e fui aprovado no teste pelo Manoel Carlos”). É bastante evidente nessa construção o quanto o discurso terapêutico interpela o indivíduo como um sujeito sofredor, uma vítima que deve buscar a recuperação com o melhor autogerenciamento emocional possível. Dessa forma, é possível, como comentou a psicanalista no programa, o desenvolvimento de exercícios que possam 
aumentar a capacidade de resiliência às discriminações e violências cotidianas desfazendo-se da natureza social delas em prol do viés psicológico, objetificado e individualizante do self.

No programa exibido no dia 23 de abril de 2015, o ator Lucas Salles e o cantor Thiago Brava reconheceram o quanto o trabalho foi importante para superem seus problemas pessoais. O ator comentou que "sofria bastante bullying por causa do peso”, mas também por ser considerado “um pouco lento para aprender a matéria”. Por isso, além de ser chamado de gordo e baleia pelos colegas, era apontado como burro e lerdo, inclusive pelos professores. Mas ele comenta que teve um "grande treinamento" em sua vida: o humor. O teatro, segundo ele, permitiu que ele ficasse "bem mais rápido nas repostas". Thiago Brava também se identifica com o ator e diz que frequentemente era chamado de "custoso", pela sua dificuldade com a aprendizagem. Segundo ele, o sucesso com a música foi a possibilidade de "mostrar até mesmo para os seus professores" que ele "tinha jeito na vida". Nesse ponto, é interessante observar o quanto o discurso terapêutico produz o entendimento de que diferentes âmbitos e atividades cotidianas (como fazer teatro, trabalhar, estudar música) se tornem terapias de recuperação e aperfeiçoamento pessoais. Há algo bastante semelhante no relato de Marcelo Serrado no dia 10 de março de 2015. O ator, quando criança, era "extremamente gago". Foi estudando teatro que ele conseguiu "superar a gagueira" e se tornar ator. Não se trata mais de se curar, sarar ou melhorar, mas, sobretudo, de superar os problemas. A substituição recorrente da expressão curar por superar revela o quanto no contexto contemporâneo as ações individuais passam a ser mais vistas como resultados da escolha dos indivíduos do que parte de processos sociais complexos.

A ex-jogadora de vôlei Ana Paula Herckel foi ao programa do dia 13 de agosto de 2015 anunciar que estava escrevendo um livro sobre a sua experiência pessoal com bullying. Impressionada, Fátima Bernardes indagou que era difícil imaginar que para a "uma das grandes musas do vôlei e do esporte de uma maneira geral" tenha sido vítima do bullying. A ex-jogadora logo trata de explicar que sofreu muito com o bullying, porque era "magra e alta demais". Para ela, foi o esporte que 
lhe deu autoestima. Por meio dele, pode ter um corpo mais torneado e deixou de ser considerada feia para, pelo contrário, ser considerada bonita.

É muito curioso observar que nesses relatos há uma imagem do trabalho como o casulo que permite a metamorfose da lagarta em borboleta [2]. É como se o trabalho associado à cultura do espetáculo (como o de ator, cantor ou esportista) tivesse sido uma liberação do verdadeiro eu. Leonardo Miggiorin obteve reconhecimento do seu talento e trabalhou em várias novelas inclusive como galã, depois de ter sofrido sido hostilizado na escola por ter a pele acneica. Marcelo Serrado superou a gagueira e tornou-se ator. Ana Paula Herckel sagrou-se musa do vôlei feminino pelo talento e beleza.

\section{Considerações finais}

Sem dúvida, a autoestima como conceito psicológico que se populariza na vida social contemporânea, em especial por meio de produtos da cultura da mídia como programas de televisão, fornece padrões normativos para experiência de infortúnios como os ocasionados por situações de bullying. Nas narrativas testemunhais das celebridades no programa Encontro com Fátima Bernardes, é possível identificar uma retórica da salvação pessoal no contexto da cultura contemporânea. Há uma mudança moral: de um ethos protestante de salvação através de abnegação em direção a um ethos terapêutico que procura salientar a autorrealização neste mundo. Trata-se, portanto, de um ethos caracterizado por uma enorme preocupação tanto com saúde psíquica quanto com a física em termos radicais (LEARS, 1983). O ethos terapêutico promove a produção de sujeitos preocupados com seu próprio bem-estar físico e emocional.

É certo que todas as culturas, antigas e modernas, provavelmente já tiveram algum tipo de dimensão terapêutica. Em outros tempos e outros lugares, a busca pela saúde tinha ocorrido dentro das estruturas comunais, éticas ou religiosas maiores. No final do século XIX, esse quadro começou a se transformar (LEARS, 1983). A busca pelo bem-estar e pela qualidade de vida passou a se associar com a 
autoestima, mas também com os princípios de autoaceitação, autorrealização e autoprimoramento (FUREDI, 2004).

É possível perceber de modo bastante agudo nos relatos das celebridades analisados neste artigo que há na sociedade contemporânea uma exigência para demonstrar a si mesmo como um ser vulnerável, mas, ao mesmo tempo, em constante recuperação. Não se trata somente de uma valorização demasiada de uma recuperação processual ao invés da cura, mas sobretudo de uma conformação da sobrevivência como um princípio normativo para a subjetividade contemporânea. Ou seja, enquanto a ideia de recuperação contínua (de nunca estarmos recuperados o suficiente em relação aos eventos de sofrimento, mas de termos de estar em tratamento e recuperação permanentes) reforça a sensação de vulnerabilidade (de viver constantes ameaças à segurança psíquico-ontológica pela própria experiência da vida), como bem formulou Furedi (2004), há ainda uma outra característica subjetiva socialmente valorizada: a capacidade de sobreviver aos infortúnios. Os sobreviventes já tiveram em algum momento suas existências marcadas pela extrema violência, em eventos-limite da experiência humana como catástrofes, genocídios, extrema miséria, guerras e atentados terroristas. O testemunho já foi concebido primordialmente como prova da sobrevivência da experiência como narrativa e não apenas dos sujeitos, vivos em detrimento de muitos outros que morreram em situações trágicas. O testemunho como gênero discursivo de expressão subjetiva ampliou-se, ao passo que a própria condição de vítima e o sentido de trauma se espalhou por diversos aspectos da vida cotidiana no contexto do intenso espraiamento do discurso terapêutico na cultura (FUDERI, 2014). Há, contemporaneamente, também, como abordei pelos testemunhos considerados, uma nova significação da sobrevivência: a sobrevivência como resiliência e o sobrevivente como resiliente.

\section{Notas}

[1] Disponível em: <http://gshow.globo.com/programas/encontro-com-fatima-bernardes/>. Acesso em: 18 dez. 2017.

[2] Lançado no Brasil em 2004, o livro De lagarta a borboleta: um caminho para a transformação interior, das psicólogas Wilma Ruggeri e Maria Salette, trata da 
"transformação necessária da lagarta que somos para a borboleta que almejamos e podemos ser" (RUGGERI e SALETTE, 2004, p.2). Não estou querendo afirmar que as celebridades convidadas para o programa leram esse livro, mas assinalar o quanto há de circulação da linguagem terapêutica, pregando o autogoverno e a autoestima como forma necessária para o desenvolvimento pessoal, em vários âmbitos da cultura da mídia.

\section{Referências}

APPIAH, Kwame A. Identity, authenticity, survival: multicultural societies and social reproduction. In: GUTMANN, Ann (Ed.). Multiculturalism: examining the politics of recognition. Princeton: Princeton University Press, 1994, p.149-164.

BEVERLEY, John. Testimonio: on politics of the truth. Minneapolis: University of Minesota Press, 2004.

BINKLEY, Sam. Psychological life as enterprise: social practice and government of neo-liberal interiority. History of the Human Sciences, vol.24, n.3, p.83-102, 2011.

CRUIKSHANK, Barbara. Revolutions within: self-government and self-esteem. In: BARRY Andrew, OSBORNE, Thomas e ROSE, Nikolas (Eds.) Foucault and Political Reason. London: Routledge, 1996, p.231-251.

FUREDI, Frank. Therapy culture: cultivating vulnerability in an uncertain age. London: Routledge, 2004.

HERMAN, Joseph. Trauma and Recovery. New York: Basic Books, 1992.

ILLOUZ, Eva. O amor nos tempos do capitalismo. Rio de Janeiro: Jorge Zahar Editor, 2012.

. Oprah Winfrey and the glamour of misery: an essay on popular culture. New York: Columbia University Press, 2003.

LEARS, T. J. From salvation to self-realization: advertising and the therapeutic roots of the consumer culture, 1880-1930. In: WIGHTMAN, Richard; LEARS, T. J. (Orgs.). The culture of consumption: critical essays in American History, 1880-1980.New York: Pantheon Books, 1983, p.1-38.

LIPOVESTKY, Gilles. Metamorfoses da cultura liberal: ética, mídia, empresa. Porto Alegre: Sulina, 2004.

LITTLER, Jo. Making fame ordinary: intimacy, reflexivity, and 'keeping it real'. Meditative: ideas/knowledge/culture, v. 1, n.2, p.8-25, 2004. 
MORIN, Edgar. Cultura de massa no século $X X$

- neurose. São Paulo : Forense Universitária, 1977. 